\title{
Editorial Announcement
}

\section{Special Issue on the Behavioral Functions of the Locus Coeruleus}

The third special edition of Physiological Psychology during my tenure as editor will be published in June 1985, and the topic will focus on the behavioral functions of the locus coeruleus (LC). Papers that will be included in this issue were based on a Round Table that was organized by Susan J. Sara, C.N.R.S., Gif sur Yvette, France, at the 1984 European Brain and Behavior Society's workshop on Brain Plasticity, Learning, and Memory. The theme of these papers centered on the LC, catecholamines, memory, and selective attention. The participants were Gary Aston-Jones, B. J. Everitt, T. Kasamatsu, Robert Oades, T. W. Robbins, Susan J. Sara, Menahem Segal, and Lydia Velley.

I would like to encourage those of you who are engaged in research pertaining to the behavioral function of the LC to submit manuscripts to me before April 1985 to be considered for publication in the special issue. We welcome contributions from neuropsychological, neuroanatomical, electrophysiological, neuropharmacological, and clinical perspectives. Papers on topics other than the LC and behavior that are currently in the process of editorial review or publication will not be delayed.

Patricia Morgan Meyer

Editor 